\title{
The Effectiveness of Heart Valve Replacement Surgery in a Non-Referral Regional Hospital: The Analysis of Outcomes after Isolated and Complex Valve Replacement
}

\author{
Mehmet Erin Tüysüz, ${ }^{1}$ Mehmet Dedemoğlu ${ }^{2}$ \\ Departments of ${ }^{1}$ Cardiovascular Surgery and ${ }^{2}$ Pediatric Cardiovascular Surgery, Mersin City Education and Research Hospital, Mersin, \\ Turkey
}

\section{ABSTRACT}

Background: To comprehensively investigate early and late outcomes for all valve replacement surgery patients in a non-referral regional hospital database and to compare these results with the literature.

Methods: This was a retrospective study and made up of patients undergoing heart valve replacement in the cardiovascular department of a non-referral regional hospital between May 2008 and February 2018. Inclusion criteria were aortic, mitral and double valve replacement with or without CABG.

Results: 212 patients were included in the study. Of the 212 patients, 65 were aortic valve replacement, 119 were mitral valve replacement, 28 were double valve replacement patients. Mean follow-up of all patients was $3.4 \pm 2.9$ years. There was no significant difference among the groups regarding hospital mortality. The occurrence of acute renal failure and neurological event was the main factors of morbidity-associated mortality. Concomitant CABG procedure was found to be an independent predictor of early mortality after MVR. In the AVR group, there was no significant difference between AVR with CABG and without $\mathrm{CABG}$ regarding the 5-year survival rates; whereas in MVR and DVR group, there was a statistically significant difference between the groups. According to Cox proportional hazards model for determining factors related to late mortality, preoperative chronic renal failure and concomitant CABG were factors independently related to late mortality after MVR.

Conclusion: We believe that our study will contribute to the development of the outcomes of heart valve replacement surgery in these centers by supporting other non-heart center clinics in working toward acceptable morality rates for complex valve surgeries.

\section{INTRODUCTION}

Since the first successful aortic and mitral valve replacement in 1960, significant progress has been made in this

Received fanuary 6, 2019; received in revised form April 11, 2019; accepted fune 13, 2019.

Correspondence: Mebmet Dedemoğlu, MD, Mersin City Training and Research Hospital, Korukent dist. 96015 St, Mersin/Turkey 33240; +90-532-7907218 (e-mail: mehmetdedemoglu@gmail.com). area with the help of the developments of surgical technique and postoperative care [Braunwald 2003]. As a result, these operations have been performed with very low mortality and morbidity rates [Birkmeyer 2000; Hassan 2004]. In addition to this, long-term survival and health-related quality of life data are also available in the literature, even though they are limited [Ruel 2007; Noyez 2011]. However, the early and/or long-term outcomes after heart valve replacement have been obtained primarily from the data of heart centers which are referral hospitals. It is an undeniable fact that there is a direct relationship between the success of surgery and high patient/ surgeon-volume hospitals such as tertiary hospitals that are specialized in their area [Dewey 2012]. Cardiac surgery is also performed in non-referral hospitals and multidisciplinary state hospitals as well as in the tertiary heart centers and medical faculty hospitals. Because the tertiary hospitals are unable to meet high demand and patients cannot easily reach these hospitals, secondary regional hospitals are obligated to provide health services to the people in their region.

Studies on heart valve surgery in non-referral hospitals are quite few. To the best of our knowledge, there are little to no reports including comprehensive analysis of results regarding isolated and/or double heart valve replacement with or without concomitant coronary artery bypass grafting $(\mathrm{CABG})$ in a non-referral hospital. The purpose of this study is to evaluate comprehensively early and late outcomes for all valve replacement surgery patients in a non-referral regional hospital database and to compare these results with the literature.

\section{MATERIALS AND METHODS}

\section{Patients}

This was a retrospective observational cohort study made up of patients undergoing heart valve replacement in the cardiovascular department of a secondary regional hospital between May 2008 and February 2018. The hospital registry database was searched to reveal patients undergoing heart valve replacement surgery. Inclusion criteria were aortic and mitral valve replacement (AVR, MVR) with or without CABG, double valve replacement (DVR) with or without CABG; exclusion criteria were valve repair procedures, emergency cardiac surgery interventions, preoperative intubation, additional aortic procedures (Benthall procedure, etc.), 
Table 1. Baseline Characteristics of All Patients

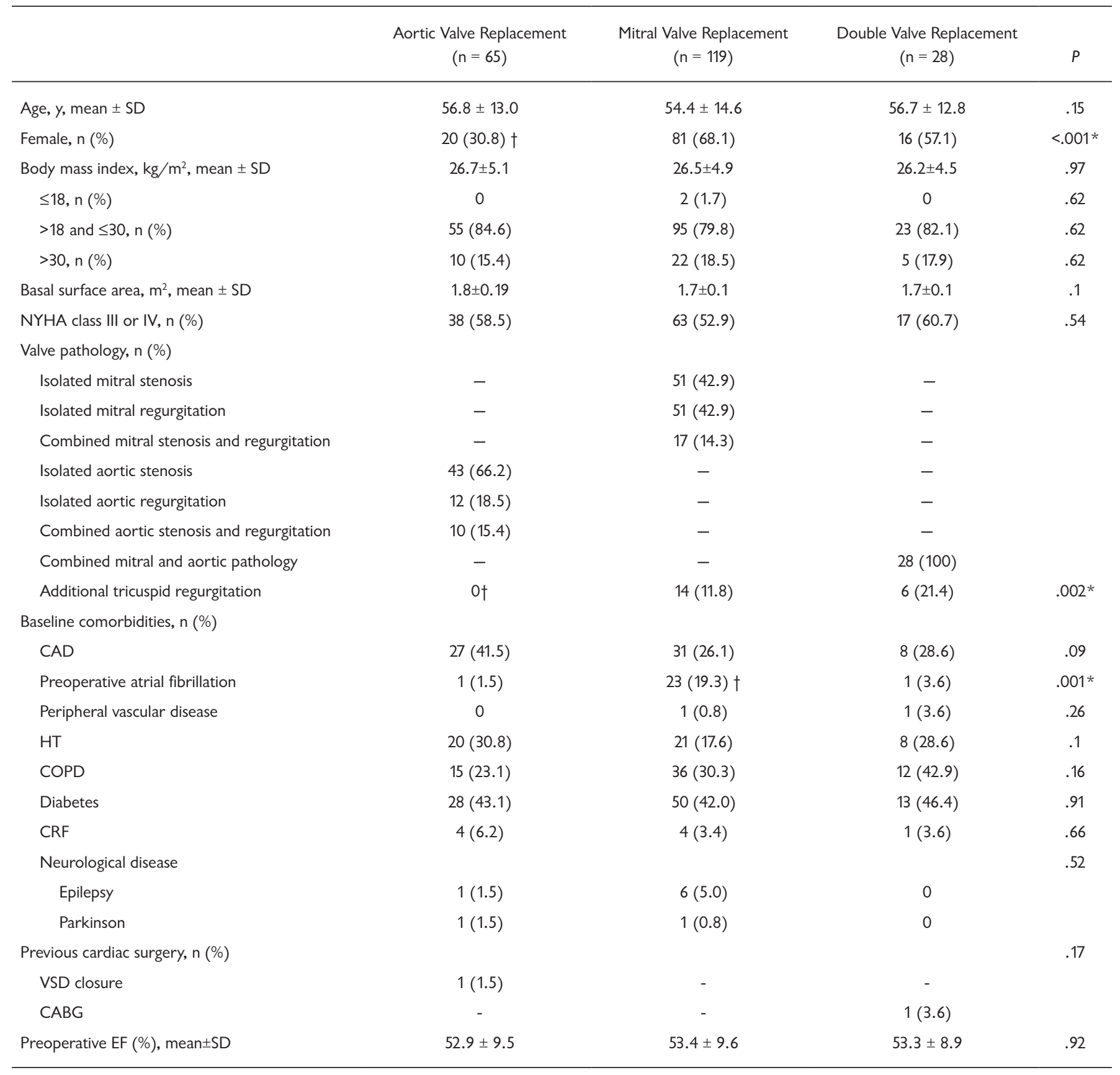

CABG indicates coronary artery bypass grafting; $C A D$, coronary artery disease; $C H F$, congestive heart failure; COPD, chronic obstructive pulmonary disease; CRF, chronic renal failure; EF, ejection fraction; HT, hypertension; MI, myocardial infarct; NYHA, New York Heart Association; VSD, ventricular septal defect. * Statistically significant parameter.

†The group causing the difference.

combined valve replacement and complex cardiac surgery, additional carotid artery surgery, and valve repair or replacement due to infective endocarditis.

All operations were performed under cardiopulmonary bypass with standard cardiac surgery and moderate hypothermia was applied. Cardioplegia administration was applied with the help of cold blood solution. Mechanical prosthetic valve replacement was the most frequently applied method, while biological prosthetic valve replacement was performed in patients with elder age or in cases of a woman 
Table 2. Operative Variables

\begin{tabular}{|c|c|c|c|c|}
\hline Concomitant tricuspid valve repair, n (\%) & $\dagger$ & & & $.001 *$ \\
\hline TDVA & 0 & $13(10.9)$ & $5(17.9)$ & \\
\hline Aortic valve no, median (ranges) & $21(19-27)$ & - & $21(19-23)$ & .62 \\
\hline Mitral valve no, median (ranges) & - & $27(25-33)$ & $27(21-33)$ & .99 \\
\hline Biological valve replacement, n (\%) & $\dagger$ & & & $.02 *$ \\
\hline Aortic valve & $4(6.2)$ & - & 0 & \\
\hline Left atrial plication & $1(1.5)$ & $10(8.4)$ & $1(3.6)$ & \\
\hline Cryoablation & 0 & $1(0.8)$ & 0 & \\
\hline Hypothermia, oC, mean \pm SD & $28.7 \pm 1.1$ & $29.0 \pm 1.1$ & $28.2 \pm 0.5 \dagger$ & $.002 *$ \\
\hline Cross-clamp time, min, mean \pm SD & $117.8 \pm 36.1$ & $97.4 \pm 31.4$ & $173.6 \pm 51.1 \dagger$ & $<.001 *$ \\
\hline $\mathrm{CPB}$ time, min, mean $\pm \mathrm{SD}$ & $154.4 \pm 47.1$ & $127.8 \pm 41.3$ & $208.4 \pm 58.9 \dagger$ & $<.001 *$ \\
\hline Retrograde cardioplegia, n (\%) & $13(20.0)$ & $6(5.0)$ & $13(46.4) \dagger$ & $<.001 *$ \\
\hline
\end{tabular}

CABG indicates coronary artery bypass grafting; CPB, cardiopulmonary bypass; RFA, radio frequency ablation; TDVA, tricuspid de vega annuloplasty.

* Statistically significant parameter.

†The group causing the difference.

considering pregnancy. Warfarin as an oral anticoagulant was recommended as a long-life treatment to all patients with a mechanical valve and to patients with permanent atrial fibrillation $(\mathrm{AF})$, while they were prescribed as a three-month treatment to patients with a biological valve.

Patient demographics and laboratory or imaging results were recorded to reveal baseline patient characteristics. Primary outcome of interest was surgically related early mortality (within 30 days) and its predictors, late survival rates during the follow-up, and a determination of predictor factors for late survival. Secondary outcomes of interest were potential complications, including $\mathrm{AF}$ and other arrhythmias, reoperation for bleeding, low cardiac output syndrome (which was defined as persistent hypotension, central venous pressure increase, low urine output and high dose inotrope need), sternal wound infection, sepsis, respiratory complications, acute renal failure, prolonged duration of intensive care unit and hospital stay. In addition, The National Death Notification System was used to confirm death information of patients who died during follow-up and to obtain their death dates.

\section{Statistical Analysis}

Continuous data following a normal distribution were expressed as mean and standard deviation, while ones not following a normal distribution were expressed as median and ranges. Categorical variables were reported as frequency and percentage. The groups were compared by using one-way analysis of variance (ANOVA) for continuous data following a normal distribution, Kruskal Wallis test for continuous data not following a normal distribution and Pearson chi-square test for categorical variables. 'Bonferroni correction' and 'Post Hoc tests' were utilized for checking the analyses.

In the analysis of predictive risk factor for early mortality, univariate predictors were determined with univariate logistic regression analysis and an odds ratio was calculated for each parameter. Variables having a $P$ value $<.10$ in the univariate analysis and non-correlated to each other were included into the multivariate logistic regression analysis. The appropriateness of model was tested using Forward: Wald approach. Factors with $P$ values less than .05 were considered significantly related to early death.

Any deaths after discharge from the initial hospitalization were defined as late mortality. Long-term survival curves were computed using Kaplan-Meier method and Log-rank test was used to compare survival rates of patients with and without additional CABG procedure. Cox proportional hazard regression with the help of a Backward-LR approach was used to compute hazard ratios (HR) and $95 \%$ confidence 
Table 3. Postoperative Outcomes

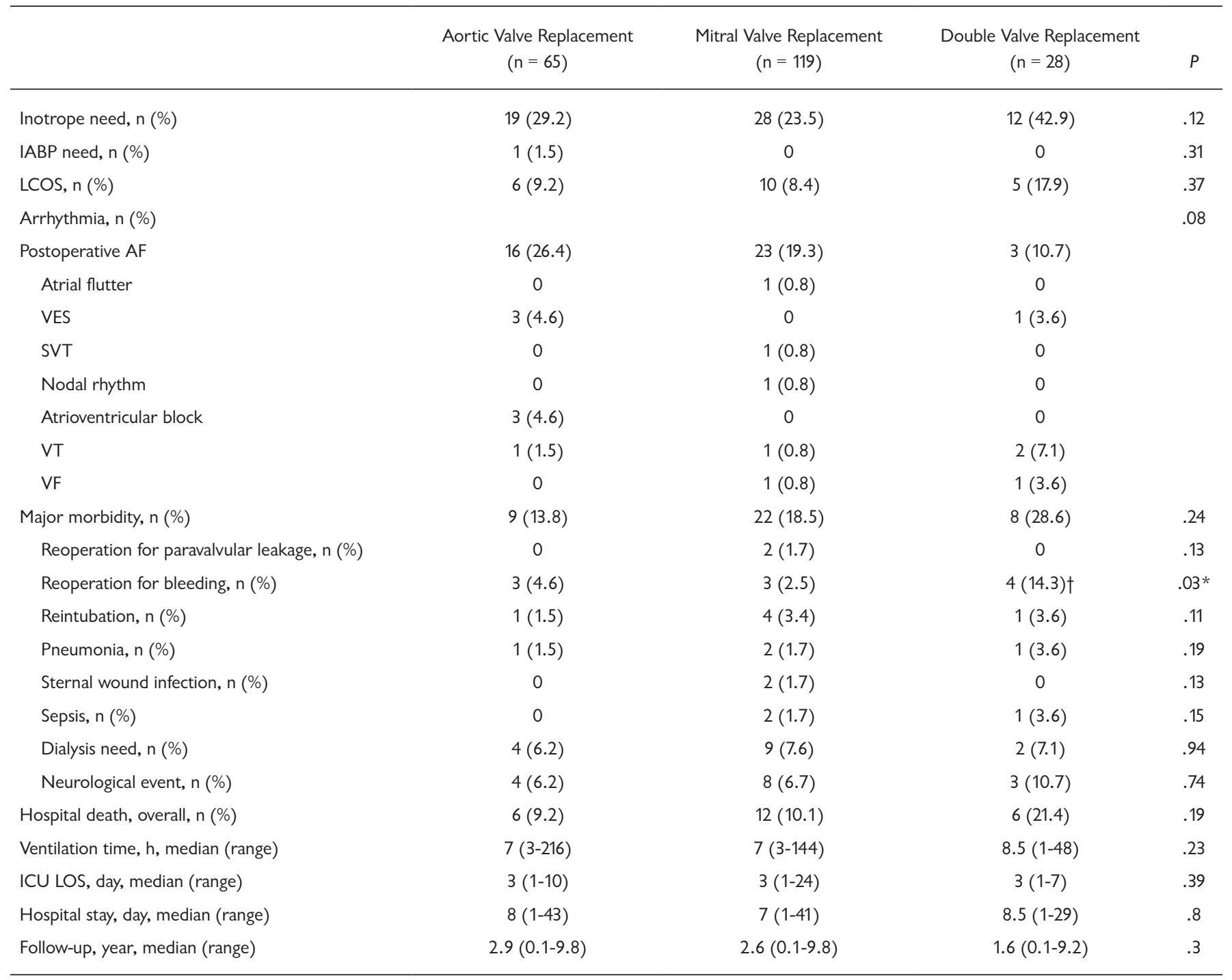

AF indicates atrial fibrillation; CABG, coronary artery bypass grafting; IABP, intraaortic balloon pump; ICU LOS, intensive care unit length of stay; LCOS, low cardiac output syndrome; SVT, supra-ventricular tachycardia; VES, ventricular extra systole; VF, ventricular fibrillation; VT, ventricular tachycardia.

* Statistically significant parameter.

†The group causing the difference.

intervals $(\mathrm{CI})$ for determining risk factors related to late mortality. $P<.05$ was defined as statistically significant.

\section{RESULTS}

212 patients were included in the study. Mean age was 56.0 \pm 13.9 years (range $20-89$ years) and $117(55.2 \%)$ patients were female. Of the 212 patients, 65 had aortic valve replacement (AVR), 119 had mitral valve replacement (MVR), 28 had double valve replacement (DVR). Mean follow-up of all patients was $3.4 \pm 2.9$ (median: 2.6, min: 0.1, max: 9.8) years. The baseline characteristics of all patients are listed in Table 1. Patients characteristics were similar among the procedural groups. There was a male patient dominance in the AVR group $(P<.001)$. Patients undergoing MVR had higher preoperative atrial fibrillation rates compared to the other groups $(P=.001)$. Similarly, patients undergoing MVR and DVR had additional tricuspid valve pathology $(P=.002)$, whereas there was no pathology in those undergoing AVR.

Operative data are demonstrated in Table 2. There were 59 patients $(27.8 \%)$ who underwent concomitant CABG procedure and it was significantly higher in AVR group $(P$ $=.03)$. Tricuspid valve repair was performed in $20(9.4 \%)$ patients who were from MVR and DVR groups $(P=.001)$. Biological prosthetic valve was used in 6 patients $(2.8 \%)$, and 
Table 4. Hospital and Long-Term Mortality Rates, Durations of ICU and Hospital Stays According to the Concomitant CABG Performed

\begin{tabular}{|c|c|c|c|}
\hline AVR & $(\mathrm{n}: 26)$ & (n: 39) & \\
\hline Long term mortality, n (\%) & $3(11.5)$ & $8(20.5)$ & .34 \\
\hline ICU LOS, day, median (range) & $3(1-5)$ & $3(1-10)$ & .27 \\
\hline MVR & $(\mathrm{n}: 26)$ & (n: 93) & \\
\hline Hospital mortality, n (\%) & $8(30.8)$ & $4(4.3)$ & $<.001 *$ \\
\hline Long term mortality, n (\%) & $6(23.1)$ & $12(12.9)$ & .20 \\
\hline ICU LOS, day, median (range) & $4(1-24)$ & $3(1.14)$ & $.02 *$ \\
\hline Hospital stay, day, median (range) & $12(1-41)$ & $7(1-40)$ & .07 \\
\hline ICU LOS, day, median (ranges) & $3.5(1-4)$ & $3(1-7)$ & .70 \\
\hline Hospital stay, day, median (range) & $7(1-29)$ & $9(1-21)$ & .50 \\
\hline
\end{tabular}

AVR indicates aortic valve replacement; CABG, coronary artery bypass grafting; DVR, double valve replacement; ICU LOS, intensive care unit length of stay; MVR, mitral valve replacement.

*Statistically significant parameter

it was significantly higher in AVR group $(P=.02)$. Additional cardiac procedures were due to preoperative atrial fibrillation, which was performed in 25 patients $(11.8 \%)$ who were mostly in MVR group $(P=.004)$. Of those, $13(6.1 \%)$ patients turned to the sinus rhythm after the operation. Cross clamp and CPB times were significantly higher $(P<.001$ in both $)$, hypothermia degree was significantly lower $(P=.002)$ in the DVR group compared to the others. And the rate of retrograde cardioplegia administration was significantly higher in DVR group $(P<.001)$.

In the postoperative period, there was no any mismatch of mechanical valve in patients. Two patients underwent reoperation for paravalvular leakage in MVR group. Overall unadjusted mortality rate was $11.3 \%$ (24 patients), and major morbidity rate was $18.4 \%$ (39 patients). When the major morbidity was observed, the associated unadjusted mortality increased from $6.9 \%$ to $30.8 \%$ (OR: 6.0, 95\% CI: 2.4-14.6, $P<.001)$. The occurrence of any acute renal failure was associated with an increased unadjusted mortality to $53.3 \%$ of patients, compared with $8.1 \%$ without this complication (OR: $12.9,95 \%$ CI: $4.2-40.3, P<.001)$. In addition to this, the occurrence of any neurological event was also associated with an increased unadjusted mortality to $46.7 \%$ of patients, compared with $8.6 \%$ without this event (OR: 9.3, 95\% CI: 3.028.7, $P<.001$ ). These findings show that acute renal failure and neurological event complications proved to be the main factors of morbidity-related mortality. Postoperative outcomes regarding procedural groups are depicted in Table 3.
Hospital mortality rate was higher in those undergoing DVR compared to those undergoing isolated valve replacement (21.4\%); however, there was no statistically significant difference among the groups. The rate of reoperation for bleeding was significantly higher in DVR group $(P=.003)$. There was no significant difference in terms of the other postoperative complications among the groups. Duration of ICU was similar in all procedural groups. Durations of ventilation time and hospital stay were higher in DVR, although there was no significant difference.

In Table 4, hospital and long-term mortality rates, and durations of ICU and hospital stays according to the concomitant CABG surgery are demonstrated. These rates and durations were mostly higher in groups with concomitant CABG, although there was no significant difference in most of them. Hospital mortality rate and the duration of ICU stay were significantly higher in MVR group with concomitant CABG compared to without concomitant CABG $(P<.001$ and $P=$ .02 respectively). The causes of early mortality are also demonstrated in Table 5.

Multivariate analysis for determining factors related to early mortality was used in only MVR group due to the fact that there was not enough sample size to apply this analysis in AVR and DVR groups. In multivariate analysis, concomitant CABG procedure was found to be an independent predictor of early mortality after MVR (OR: 10.08, 95\% CI 2.66-38.13, $P=.001$ ).

In the late period, estimated mean survival times of procedural groups were listed in Table 6. 5-year survival rate in 
Table 5. Causes of Early Mortality

\begin{tabular}{lccc}
\hline Cause of mortality & $\begin{array}{c}\text { Aortic Valve Replacement } \\
(\mathrm{n}=65)\end{array}$ & $\begin{array}{c}\text { Mitral Valve Replacement } \\
(\mathrm{n}=119)\end{array}$ & $\begin{array}{c}\text { Double Valve Replacement } \\
(\mathrm{n}=28)\end{array}$ \\
\hline LCOS, $\mathrm{n}(\%)$ & $4(6.2)$ & $3(2.5)$ & $3(10.7)$ \\
MOF, $\mathrm{n}(\%)$ & - & $3(2.5)$ & - \\
Interventricular grove rupture, $\mathrm{n}(\%)$ & - & $2(1.7)$ & - \\
CVA, $\mathrm{n}(\%)$ & $1(1.5)$ & $2(1.7)$ & $1(3.6)$ \\
Sepsis, $\mathrm{n}(\%)$ & - & - & - \\
Bleeding diathesis, $\mathrm{n}(\%)$ & $1(1.5)$ & - & $1(3.6)$ \\
Malign arrhythmia, $\mathrm{n}(\%)$ & - & - & $1(3.6)$ \\
Respiratory complication, $\mathrm{n}(\%)$ & - & - \\
\hline
\end{tabular}

CVA indicates cerebrovascular accident; LCOS, low cardiac output syndrome; MOF, multi-organ failure.

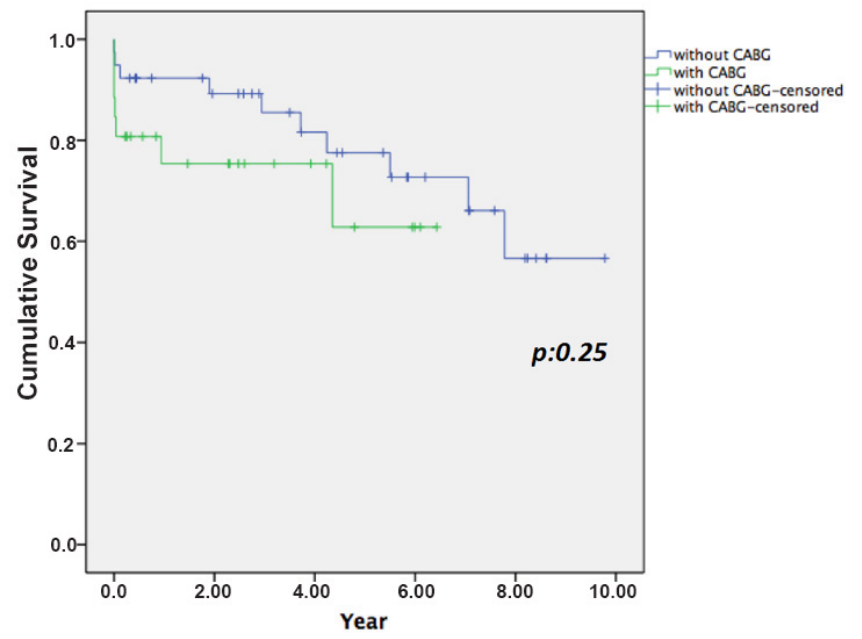

Figure 1. Survival curves of patients undergoing aortic valve replacement with and without concomitant coronary artery bypass grafting.

AVR without concomitant CABG was $77.5 \%$, while 5-year survival rate was $62.8 \%$ in AVR with concomitant CABG. Regarding survival rates, there was no significant difference between AVR with CABG and without CABG groups $(P=$ $.25, \log$-rank), and survival curves are also demonstrated in Figure 1. In patients undergoing MVR without concomitant CABG, 5 -year survival rate was $79.0 \%$, whereas in those undergoing MVR with concomitant CABG, 5-year survival rate was $48.1 \%$ (Figure 2), and there was statistically significant difference between the two groups $(P<.001$, log-rank). When comparing survival rates according to DVR group, 5 -year survival rate was $65.3 \%$ in DVR without CABG group. 5 -year survival rate was $28.6 \%$ in those with CABG and there was statistically significant difference between the two groups $(P=.03, \log$-rank) (Figure 3$)$.

Cox proportional hazards model for determining factors related to late mortality was used in only MVR group due



Figure 2. Survival curves of patients undergoing mitral valve replacement with and without concomitant coronary artery bypass grafting.

to the fact that there was not enough sample size to apply this analysis in AVR and DVR groups. In multivariate analysis, preoperative chronic renal failure (HR: 8.3, 95\% CI: 1.6-42.3, $P=.01$ ) and concomitant CABG (HR: 5.7, 95\% CI: $2.1-15.4, P=.001)$ were factors independently related to the late mortality after MVR. Survival curves associated with independent risk factors are depicted in Figure 4.

\section{DISCUSSION}

Outcomes of heart valve replacement have improved over time [Rankin 2006; Panda 2009; Maleszka 2008; David 2008; Nowicki 2004]. However, the outcomes given are mostly obtained from referral-heart surgery centers, whereas the outcomes obtained from non-heart surgery centers are rather few. Our study reflects the results of heart valve replacement 
Table 6. Estimated Mean Survival Times of Procedural Groups

\begin{tabular}{lccc}
\hline & Mean survival time, $y$ & $\begin{array}{c}95 \% \mathrm{Cl} \\
\text { (lower) }\end{array}$ & $\begin{array}{l}95 \% \mathrm{Cl} \\
\text { (upper) }\end{array}$ \\
\hline $\begin{array}{l}\text { AVR } \\
\text { Without CABG }\end{array}$ & 7.5 & 6.3 & 8.7 \\
With CABG & 4.6 & 3.5 & 5.8 \\
MVR & & & \\
Without CABG & 8.1 & 7.3 & 8.9 \\
With CABG & 4.4 & 2.8 & 6.0 \\
DVR & & & \\
Without CABG & 5.5 & 4.0 & 6.8 \\
With CABG & 2.6 & 0 & 5.7 \\
\hline
\end{tabular}

AVR indicates aortic valve replacement; $C A B G$, coronary artery bypass grafting; $\mathrm{Cl}$, confidence interval; DVR, double valve replacement; MVR, mitral valve replacement.

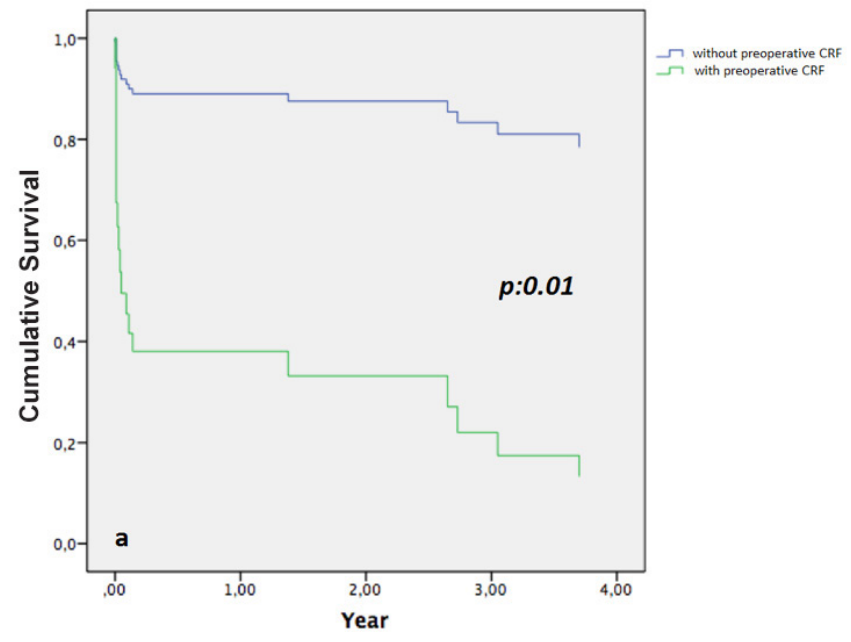

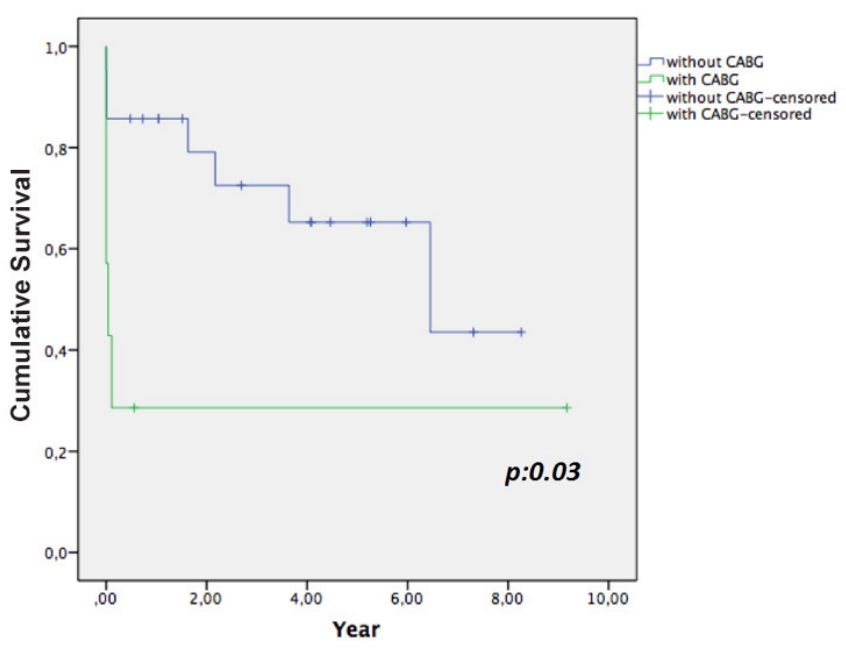

Figure 3. Survival curves of patients undergoing double valve replacement with and without concomitant coronary artery bypass grafting.

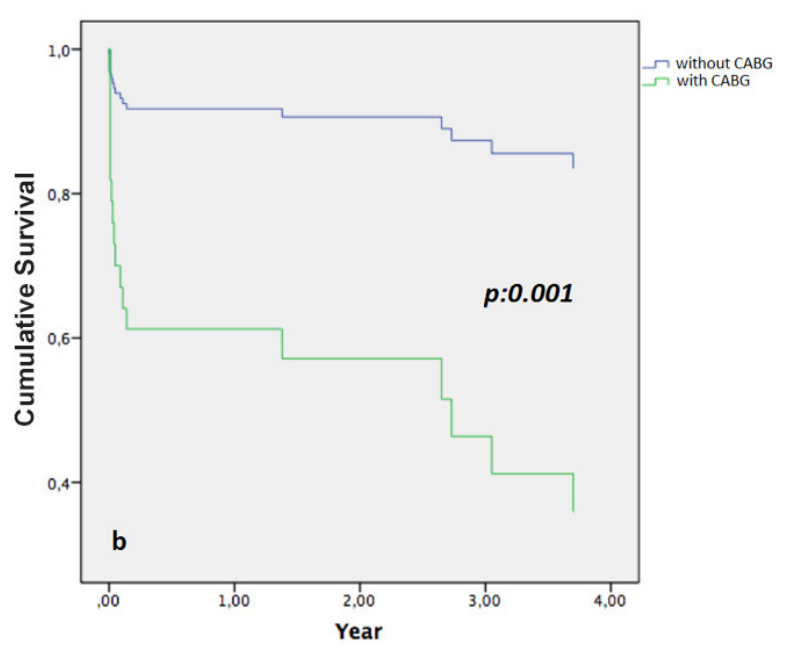

Figure 4. Survival curves associated with independent risk factors in mitral valve replacement group.

obtained from the database of a regional hospital. Overall mortality rate in our series was $11.3 \%$, while this rate in a heart center hospital is 5.6\% [Lee 2011], and is much lower compared to our series. This is a good example reflecting the disparity between high-volume tertiary heart centers and non-referral regional hospitals. On the other hands, the occurrence of postoperative morbidity was associated with increased mortality. Similarly, it has been emphasized in studies with large series that the occurrence of morbidity contributes to the increased mortality [Rankin 2017]. Particularly in our study, this relationship was stronger in the presence of postoperative acute renal failure and neurological event. Thus, it may be considered that those are the main factors of morbidity-related mortality.
Conventional aortic valve replacement is still the gold standard approach in the surgical treatment of aortic valve diseases [Walther 2012]. Early mortality rate ranges between 4.3\% and 5.9\% [Biancari 2014; Yan 2018; Stahle 1997]. In our series, early mortality rate for all AVR patients was $9.2 \%$ and higher compared to the literature. For isolated AVR, there have been decreased mortality rates [Rankin 2006; Biancari 2014]. When compared to early mortality rates for isolated AVR, the early mortality rate ranges from $3.3 \%$ to 4\% [Biancari 2014; Edwards 2001], whereas this rate is 5.1\% in our series and relatively close to the literature. The presence of concomitant CABG is among the factors influencing early mortality rates [Stahle 1997] and the frequency of concomitant CABG has been increasing [Saxena 2013]. The early 
mortality rate for AVR with concomitant CABG ranges from $5.5 \%$ to $6.8 \%$ [Biancari 2014; Edwards 2001]. In our series, this rate is $15.4 \%$ and much higher compared to the literature. In the long term, the 5-year survival rate in isolated AVR patients is $85 \%$, and while in the presence of concomitant CABG it is $73 \%$ [de Waard 2012]. The presence of concomitant CABG has a higher long-term mortality rate compared to isolated AVR [Jones 2006; Kvidal 2000]. Our study also supports this condition. These rates in our series are $77.5 \%$ and $62.8 \%$, respectively, and relatively close to the literature.

The overall early mortality rate after MVR ranges from $6.4 \%$ to $10.4 \%$ irrespective of the presence of additional procedures [Yan 2018; Stahle 1997; Thourani 2003], while overall early mortality for MVR in our series is $10.1 \%$. On the other hand, a reduced mortality is present in the isolated MVR [Bolling 2000] due to frequent application of valve repair instead of replacement [Savage 2003; Kang 2009]. The early mortality for isolated MVR ranges from $3.7 \%$ to $6.4 \%$, while this ranges from $8.7 \%$ and $15.3 \%$ in the presence of concomitant CABG [Hassan 2004; Edwards 2001; Goodney 2002; Gammie 2018; Rankin 2017]. The presence of concomitant CABG is responsible for high mortality rates after MVR. A study conducted with STS adult cardiac surgery database that included 87,214 patients and 125 centers reports that the early mortality rate is $3.7 \%$ after isolated MVR [Gammie 2018], whereas the other study conducted with STS database reports that this rate is $8.7 \%$ in MVR with concomitant CABG patients [Rankin 2017]. According to our series, the early mortality rate in isolated MVR group is $4.3 \%$ and quite satisfactory. However, this rate in MVR with concomitant $\mathrm{CABG}$ is $30.8 \%$ and rather high. This situation may be explained by the fact that patients' observed mortality had higher comorbid factors. In the long term, according to a report, the 5-year survival rate for isolated MVR is $77 \%$, whereas for MVR with concomitant CABG it is 58\% [Thourani 2003]. When looking at our study, these rates are $79 \%$ and $48.1 \%$ respectively, and there is a statistically significant difference between the two rates. The one predictive factors for long-term mortality in MVR surgery is the presence of additional CABG [Thourani 2003]. In addition, chronic renal failure (CRF) is also an independent predictor for late mortality [Murana 2018]. Similarly, the independent predictors for long term mortality after MVR were concomitant CABG and CRF in our series.

The overall mortality rate for all DVR ranges between 6.7\% and 15.5\% [Yan 2018; Stahle 1997; Nicolini 2014; Litmathe 2006], while this rate is $21.4 \%$ in our series and much higher. Many studies have documented that there is increased mortality risk in patients undergoing DVR with concomitant CABG [Hannan 2000; Hellgren 2002; Galloway 1992]. A study reports that the mortality rate is $5.7 \%$ for isolated DVR, while for DVR with concomitant CABG it is $12.5 \%$ [Nicolini 2014]. According to our series, these rates are much higher compared with it. The concomitant CABG also affects long-term survival. The same study also reports that the 5 -year survival rate is $77.5 \%$ for isolated DVR, while this rate decreases to $63 \%$ in the presence of additional CABG [Nicolini 2014]. In our series, 5 -year survival rate $(65.3 \%)$ is relatively acceptable in isolated DVR groups, whereas this rate $(28.6 \%)$ in the presence of concomitant CABG is much lower compared to the literature.

Many studies report that there is a relationship between patient and surgeon volume, and mortality [Hannan 1991; Hannan 1989; Williams 1991]. In particular, the results are much better in the high patient and surgeon volume hospitals compared with the others [Dudley 2000]. Furthermore, the mortality rate has been increasing in hospitals with low patient and surgeon volume [Birkmeyer 2003]. Our study reflects this situation perfectly. Particularly in the presence of concomitant CABG and DVR, we observe much more troubling results. The possible reason for this is due to the lack of sufficient surgical experience and postoperative care conditions of our center like other non-referral hospitals. However, heart valve surgery has also been performed in the non-referral centers and will continue to be performed because referral heart centers may not have the capacity to meet the care of all patients. To decrease the mortality in non-referral hospitals, a heart team concept like in the referral hospitals should be formed, and the design of the intensive care unit improved.

The limitations of our study are related to its retrospective and single-institutional nature. Therefore, we could not make a comparison with the results of centers like ours. In addition, we also tried to compare our results with the literature. However, in the literature, the studies that include the results of all valve replacement surgery including double valve replacement and concomitant CABG in the same report are quite low. Thus, we could not compare our results with a study similar to ours.

In conclusion, one of the purposes of our study is to demonstrate the applicability of heart valve replacement surgery in non-heart center hospitals. In these centers, the mortality rates are higher in complex surgery due to the fact that the volume of this surgery is low and there is a lack of surgical experience. Thus, as the patient volume and surgical experience increase, the success rate will also increase in these hospitals. In addition to this, better processes in the postoperative phase of care might also improve the overall results significantly. We believe that our study will contribute to the development of the results of heart valve replacement surgery in these centers by supporting other non-heart center clinics and working toward acceptable mortality rates for complex valve surgeries.

\section{REFERENCES}

Biancari F, Martin M, Bordin G, et al. 2014. Basic data from 176 studies on the immediate outcome after aortic valve replacement with or without coronary artery bypass surgery. J Cardiothorac Vasc Anesth 28:1251-6.

Birkmeyer JD, Stukel TA, Siewers AE, et al. 2003. Surgeon volume and operative mortality in the United States. N Engl J Med 349:2117-27.

Birkmeyer NJO, Marrin CAS, Morton JR, et al. 2000. Decreasing mortality for aortic and mitral valve surgery in Northern New England. Ann Thorac Surg 70:432-7.

Bolling SF, Dickstein ML, Levy JH, et al. 2000. Management strategies for high-risk cardiac surgery: improving outcomes in patients with heart 
failure. Heart Surg Forum 3:337-49.

Braunwald E. 2000. Aortic valve replacement: an update at the turn of the millennium. Eur Heart J 21:1032-3.

David TE, Armstrong S, Maganti M, et al. 2008. Clinical outcomes of combined aortic root replacement with mitral valve surgery. J Thorac Cardiovasc Surg 136:82-7.

de Waard GA, Jansen EK, de Mulder M, Vonk AB, Umans VS. 2012. Long-term outcomes of isolated aortic valve replacement and concomitant AVR and coronary artery bypass grafting. Neth Heart J 20:110-7.

Dewey TM, Herbert MA, Ryan WH, et al. Influence of surgeon volume on outcomes with aortic valve replacement. 2012. Ann Thorac Surg 93:1107-12.

Dudley RA, Johansen KL, Brand R, et al. 2000. Selective referral to high-volume hospitals: estimating potentially avoidable deaths. JAMA 283:1159-66.

Edwards FH, Peterson ED, Coombs LP, et al. 2001. Prediction operative mortality after valve replacement surgery. J Am Coll Cardiol 37:885-92.

Galloway AC, Grossi EA, Baumann FG, et al. 1992. Multiple valve operation for advanced valvular heart disease: results and risk factors in 513 patients. J Am Coll Cardiol 19:725-32.

Gammie JS, Chikwe J, Badhwar V, et al. 2018. Isolated mitral valve surgery: The Society of Thoracic Surgeons adult cardiac surgery database analysis. Ann Thorac Surg 106:716-27.

Goodney PP, Siewers AE, Stukel TA, et al. 2002. Is surgery getting safer? National trends in operative mortality. J Am Coll Surg 195:219-27.

Hannan EL, Jones RH, Gold JP, et al. 2000. Predictors of mortality for patients undergoing cardiac valve replacements in New York State. Ann Thorac Surg 70:1212-8.

Hannan EL, Kilburn H Jr, Bernard H, et al. 1991. Coronary artery bypass surgery: the relationship between inhospital mortality rate and surgical volume after controlling for risk factors. Med Care 29:1094-107.

Hannan EL, O’Donnell JF, Kilburn HJ, et al. 1989. Investigation of the relationship between volume and mortality for surgical procedures performed in New York State hospitals. JAMA 262:503-10.

Hassan A, Quan H, Newman A, Ghali WA, Hirsch GM; Team CCOR. 2004. Outcomes after aortic and mitral valve replacement surgery in Canada: 1994/95 to 1999/2000. Can J Cardiol 20:155-63.

Hellgren L, Kvidal P, Stahle E. 2002. Improved early results after heart valve surgery over the last decade. Eur J Cardiothorac Surg 22:904-11.

Jones JM, Lovell D, Cran GW, et al. 2006. Impact of coronary artery bypass grafting on survival after aortic valve replacement. Interact Cardiovasc Surg 5:327-30.

Kang DH, Kim JH, Rim J, et al. 2009. Comparison of early surgery versus conventional treatment in asymptomatic severe mitral regurgitation. Circulation 119:797-804.

Kvidal P, Bergstrom R, Horte LG, et al. 2000. Observed and relative survival after aortic valve replacement. J Am Coll Cardiol 35:747-56.

Lee R, Li S, Rankin JS, et al. 2011. Fifteen-year outcome trends for valve surgery in North America. Ann Thorac Surg 91:677-84.

Litmathe J, Boeken U, Kurt M, et al. 2006. Predictive risk factors in double-valve replacement (AVR and MVR) compared to isolated aortic valve replacement. Thorac Cardiovasc Surg 54:459-63.
Maleszka A, Kleikamp G, Zittermann A, et al. 2008. Simultaneous aortic and mitral valve replacement in octogenarians: a viable option? Ann Thorac Surg 136:82-7.

Murana G, Alfonsi J, Savini C, et al. 2018. On-X mitral valve replacement: a single-center experience in 318 patients. Interact Cardiovasc Thorac Surg doi:10.1093/icvts/ivy184.

Nicolini F, Agostinelli A, Fortuna D, et al. 2014. Outcomes of patients undergoing concomitant mitral and aortic valve surgery: results from an Italian regional cardiac surgery registry. Interact Cardiovasc Thorac Surg 19:763-70.

Nowicki ER, Birkmeyer NJ, Weintraub RW, et al. 2004. Multivariable prediction of in-hospital mortality associated with aortic and mitral valve surgery in Northern New England. Ann Thorac Surg 77:1966-77.

Noyez L, De Jager MJ, Markou ALP. 2011. Quality of life after cardiac surgery: underresearched research. Interact Cardiovasc Thorac Surg 13:511-5.

Panda BR, Shankar R, Kuruvilla KT, et al. 2009. Combined mitral and aortic valve replacement for rheumatic heart disease: fifteen-year follow up and long-term results. J Heart Valve Dis 18:170-9.

Rankin JS, Badhwar V, He X, et al. 2017. The Society of Thoracic Surgeons mitral valve repair/replacement plus coronary artery bypass grafting composite score: A report of The Society of Thoracic Surgeons quality measurement task force. Ann Thorac Surg 103:1475-81.

Rankin JS, Hammill BG, Ferguson TB, et al. 2006. Determinants of operative mortality in valvular heart surgery. J Thorac Surg 131:547-57.

Ruel M, Chan V, Bedard P, et al. 2007. Very long-term survival implications of heart valve replacement with tissue versus mechanical prostheses in adults $<60$ years of age. Circulation 116:294-300.

Savage EB, Ferguson TB, DiSesa VJ. 2003. Use of mitral valve repair: analysis of contemporary United States experience reported to the Society of Thoracic Surgeons National Cardiac database. Ann Thorac Surg 75:820-5.

Saxena A, Dinh D, Smith JA, Reid CM, Shardey GC, Newcomb AE. 2013. Excellent short- and long-term outcomes after concomitant aortic valve replacement and coronary artery bypass grafting performed by surgeons in training. J Thorac Cardiovasc Surg 145:334-40.

Stahle E, Kvidal P, Nyström SO, Bergström R. 1997. Long-term relative survival after primary heart valve replacement. Eur J Cardiothorac Surg 11:81-91.

Thourani VH, Weintraub WS, Guyton RA, et al. 2003. Outcomes and long-term survival for patients undergoing mitral valve repair versus replacement: effect of age and concomitant coronary artery bypass grafting. Circulation 108:298-304.

Walther T, Blumenstein J, van Linden A, et al. 2012. Contemporary management of aortic stenosis: Surgical aortic valve replacement remains the gold standard. Heart 98(Supp 4):iv23-9.

Williams SV, Nash DB, Goldfarb N. 1991. Differences in mortality from coronary artery bypass graft surgery at five teaching hospitals. JAMA 266:810-5.

Yan W, Shah P, Hiebert B, et al. 2018. Long-term non-institutionalized survival and rehospitalization after surgical aortic and mitral valve replacements in a large provincial cardiac surgery centre. Interact Cariovasc Thorac Surg 27:131-38. 